\title{
Generational Change and the Military Dictatorship in Brazil: The Debate on the "AI-5 Generation"
}

\author{
Silvana Seabra Hooper \\ Graduate Program-Education, Arts, and History of Culture, Mackenzie Presbyterian University, São Paulo, Brazil \\ Email: silvana.seabra@mackenzie.br
}

How to cite this paper: Hooper, S. S. (2016). Generational Change and the Military Dictatorship in Brazil: The Debate on the "AI-5 Generation". Creative Education, 7, 2338-2351.

http://dx.doi.org/10.4236/ce.2016.715226

Received: August 3, 2016

Accepted: September 26, 2016

Published: September 29, 2016

Copyright $\odot 2016$ by author and Scientific Research Publishing Inc. This work is licensed under the Creative Commons Attribution International License (CC BY 4.0).

http://creativecommons.org/licenses/by/4.0/

\begin{abstract}
This article analyzes the issue of generational change, reviews its conceptual and historical origin in Mannheim and demonstrates the relationship between generational cohorts and traumatic historical moments. The paper focuses on a new generation in Brazil, the "AI-5 generation" (1970), which was identified by Luciano Martins (social scientist), and subsequently reconsidered by Jurandir Freire Costa (social psychanalyst). It discusses one possible reinterpretation of the concept within the context of the internationalization and modernization of that period in Brazil.
\end{abstract}

\section{Keywords}

Generation, Brazil, Modernization

\section{Introduction}

With the so called "years of lead"1 behind us, we have the necessary distance to properly access the period, and this allows us to better distinguish passing phenomena from those of more lasting influence. One category of these questions relates to generationa topic that was first raised in relation to the historical moment of the Brazilian military regime, in sociologist Luciano Martins' 1979 paper entitled “The AI-5 Generation". Martins pointed out the significant changes in the social habits of Brazilian youth of

\footnotetext{
${ }^{1}$ The expression "years of lead" was not new at the time, and is not properly speaking a Brazilian expression. The term was first used in the context of Western Europe and referred to the time of Cold War tension, as well as to the left-and right-wing terrorism that began in Italy with the "Red Brigades" and spread to France with Action Direct and, most strongly, in Germany with the "Rote Armee Fraktion", better known as the "Baader-Meinhof-Gruppe". It is not certain whether the expression refers to the use of firearms, or the film of the German film-maker Margarethe von Trotta, "Die bleierneZeit" (translated as "years of lead") 1981.

${ }^{2}$ The military regime began with the military coup on March 31, 1964 and lasted until 1985. In the history of Brazil, the period was marked by the suspension of democracy, the practice of censorship and political persecution and repression of those who opposed the regime.
} 
that time, and attributed these to the instauration of the nation's military regime. ${ }^{2}$ In 1986, psychoanalyst Jurandir Freire Costa provided a response to Martins, accepting his description but attributing the changes in the youth culture to broader factors than local politics. After this critical confrontation, the debate not only cooled off; the very terms of the discussion were redefined. More recently, the concept of generation seems to have been conflated with that of youth, and the prominence of the latter has been remarkable. Throughout the eighties and nineties, the topic of the youth dominated discussions about the social issues of democratization and processes of inclusion. This perspective shift is not exclusively Brazilian, but a response to global urges, which were well represented in 1985, when the United Nations created the International Year of Youth. More recently, because of significant mobilization of youth in public demonstrations, this conversation has once again come to the fore of academic debates (Maricato, 2013; Nogueira, 2013).

In this paper, we analyze the debate between Martins and Costa, regarding what the former identified as the AI-5 generation. Our aim is to examine each author's assumptions and analytical limitations in order to identify important points for current discussion and research on the nature of "generation", both reassessing the past and seeking to understand the present time.

\section{Generations}

The study of generations is recognized as a significant field of interest within contemporary thought. At least since the 1920s, the concept of generation has been regarded as a function of precise historical periods that, according to certain authors, may be attributed to traumatic moments (Edmunds \& Turner, 2002).

Among those in the twentieth century, the generations of the 1920s and the 1960s each generated a vast literature; the latter stands out, while the 1950s and the 1970s received very little attention. In Brazil, something similar takes place with generational studies, although during the $20^{\text {th }}$ century the " 60 s received the most attention".

The concept of "generation" has been widely disseminated, both geographically and historically. In general terms, the word refers to differences among age ranges in eastern and in western societies, a distinction that goes back to ancient times. References to the concept may be found in the Bible, as well as in contemporary human sciences. Examples of generational labels in the twentieth century include "The Beat Generation", "The Lost Generation", or, more recently, "Generations X and Y". Beginning in the 1960s, not only the idea but also the expression "generation conflict" became popular. Although the concept of generation has spread widely, this growth has not been accompanied by an equivalent expansion in theoretical concern or research (Pilcher, 1994). It is not just that studies did not go forward; they seem to have halted altogether, and there was only a resurgence in critical analysis of the subject after the end of the 1980s. After that date, many studies make reference to "youth". That adjustment must be understood as a product of a global agenda promoted by international organizations, especially the UN, which shifted its attention towards greater consideration for youth, 
promoting the exchange of research, information, experiences and policy interventions for the protection of young people all over the world. It is necessary to note that the concepts of "generation" and "youth" are not equivalent: the former describes a group of people born within a specific range of years, while the latter refers to socio-cultural groups. The concept of generation has been widely criticized by those who think it is necessary to incorporate other structural criteria, such as income, geographical aspects, and even consumption into the parameters of a generational group (Bourdieu \& Boltanski, 1981; Groppo, 2000).

Nor is there a consensus regarding the concept of youth. Many consider it to be merely a definition of time-based and biological characteristics, a stage of life separating childhood from adulthood; others, who assume that age ranges are historical constructions, assert that "youth" should be understood more as a cultural and sociological concept (Kehily, 2007).

Although there were a number of important contributions to the field prior to the twentieth century, Mannheim is considered the author who most systematically and thoroughly developed the concept of generations as a theoretical problem. His work The Problem of Generation, published in1927, is a part of the large selection of texts following the First World War, such as those of Ortega and Gasset (1923) and Pinder (1926).

For Christopher Lasch (1991), these studies, particularly the work of Ortegay Gasset (1923) and Pinder (1926), are a product of World War I.

For those who lived through the cataclysm of the First World War, disillusionment was a collective experience-not just a function of the passage from youth to adulthood but of historical events that made the prewar world appear innocent and remote. For the first time, a whole period of historical time began to take on the qualities formerly associated with childhood (Lasch, 1991: p. 107).

The generation of the twenties, the Lost Generation, as it was called by Gertrude Stein, ${ }^{3}$ seems to have been the first to exhibit generational self-awareness. In this light, the publication of Mannheim's work in 1927 is no mere coincidence, but an expression of his time, not only because it reflects a moment, but also because it attempts to use this categorization to elaborate upon the nature of the group itself.

For Mannheim, generations are formed by groups of people who, having been born in the same period of time, are affected by the same historical events over the course of their lives and education. What defines a generation, for him, is less a common birth date than participation in the same social-historical processes. Such experiences, however, are not in themselves sufficient to form a generational unit, a concrete group, or a single historical and cultural awareness. Subjects experience their own epoch in different ways, a phenomenon that Mannheim called "stratification" of experience (Mannheim, 1952: p. 297). For him, being exposed to the same time and space is not enough to understand the collective identity

${ }^{3}$ Gertrude Stein utilized this term to refer to an influential group of artists in France in the late 1920s. Those artists, most of whom were foreigners, had adopted that country, and more precisely the city of Paris, as a refuge for their artistic and philosophical work. The term became commonplace. 
This, however, is a merely mechanical and external criterion of the phenomenon of "similar location". For a deeper understanding, we must turn to the phenomenon of the "stratification" of experience (Erlebnis schichtung), just as before we turned to "memory". The fact that people are born at the same time, or that their youth, adulthood, and old age coincide, does not in itself involve similarity of location; what does create a similar location is that they are in a position to experience the same events and data, etc., and especially that these experiences impinge upon a similarly "stratified" consciousness. It is not difficult to see why mere chronological contemporaneity cannot of itself produce a common generation location. No one, for example, would assert that there was community of location between the young people of China and Germany about 1800. Only where con-temporaries definitely are in a position to participate as an integrated group in certain common experiences can we rightly speak of community of location of a generation. Mere contemporaneity becomes sociologically significant only when it also involves participation in the same historical and social circum stances (Mannheim, 1997: p. 297).

His intention with this concept was to show that the dynamics of cultural transmission do not play out in a simple, direct manner, but rather are perpetually in reflexive interaction and flux (Edmunds \& Turner, 2002). This explains why generations are not homogeneous, or even coherent groups. According to Mannheim, a single generation contains distinct generational units

The generation unit represents a much more concrete bond than the actual generation as such. Youth experiencing the same concrete historical problems may be said to be part of the same actual generation; while those groups within the same actual generation which work up the material of their common experiences in different specific ways, constitute separate generation units (Mannheim, 1997: p. 307).

The lack of synchronicity of the contemporary modernity, which Mannheim borrows from the tradition of Dilthey (1995), can be attributed to multiple factors.

Furthermore, the possibility of differences is also attributable to the fact that there is not only one definition of generational identity. In fact, for Mannheim, a generation is also constituted by the fact that there is no awareness of an intentional relationship between its participants. Generations are defined as social realities, whether or not their members are aware that they belong to or participate in them. In this sense, the condition of a generation is similar to the categories of class in Marxism, or of nation, as defined by Anderson (2008). It must, however, be stressed that the definition of a generational unit entails no reductionist determinism. Even if generational position is guaranteed by some biological rhythm, it may be referred to as a necessary exposure to the same historical period, although this does not define a generation per se. In that regard, this article raises certain relevant questions about the temporalities of each generation and its successors in relation to the character of a specific time.

\section{Generation, Trauma, and History}

To the degree that theories about generations center on aspects of cultural continuity 
and change, they also consider aspects of collective memory. Mannheim was aware of the impact that certain historical conditions, particularly traumatic events, can have in defining specific conditions. Certain events are not only shared by one generation; they constitute a kind o reminiscent basis, and can act as historical markers that separate generations. This was the case, for example, in France under Napoleon, as well as for post-World War I Germany. The phenomenon is particularly evident in the twenties, when the after math of World War I forged its members "consciously as a generation marked by history, one formed by the shared experience of this catastrophic event, and many of them projected their experience back ward and reinterpreted all of history as a conflict of generations" (Lasch, 1991: p. 107).

The consequences of these events were felt by Mannheim himself, whose mentioned essay The Problem of Generation (1927), bore witness, at a sociological level, to the influence of historical context on intellectual production. This recognition was to arise in literary works as well, such as those of F. Scott Fitzgerald, who, more than other authors, fomented a relational identity between the history of his time and his own generation. Fitzgerald called the pre-war years the period of childhood or adolescence, and the post-war years a maturity laden with disillusion. The autobiographical nature of this literary characterization can be no other than what Halbwachs called a mixture between individual and collective memory. In other words, for the writers of, the Lost Generation, "autobiography is an instrument to control the collective memory of past and present" (Hazlett, 1998: p. 207).

Beyond the studies of generations in relation to the traumatic moments of the world wars, a new school of thought has suggested that the context of globalization has generated an entirely new process in the organization of generational ideas. Therefore, its proponents argue that from the late $19^{\text {th }}$ century to the $60 \mathrm{~s}$, it is possible to relate the nature of generations to nation building. The 60 s are said to have seen the first generation of an international nature, even more so because of the impact that events in the decade have had on subsequent historical processes. The change of scale of this phenomenon is also noteworthy. Before the 1960s, generational groups were tied to and identified with conceptual stances revolving around politics or art-as is the case of the generation of writers and artists in the late nineteenth century. Over the course of the twentieth century, and most significantly after WWII, this phenomenon was shaped by diffuse cultural processes that were expressed within mass society. If the dynamics of generational formation traditionally produce a small group of intellectual elites that define the views of the general public, the identity-related processes that developed in the second half of the twentieth century appear to distance themselves from this condition and organize instead around the more diverse elements characteristic of a mass society. produce a small group of intellectual elites that define the views of the general public, the identity-related processes that developed in the second half of the twentieth century appear to distance themselves from this condition and organize instead around the more disparate elements characteristic of a mass society.

At any rate, the identification of new generational movements with historical events continues to be noteworthy from the viewpoint of social change. Historical change is 
also crucial for comprehending the processes by which generations are formed. Beside social convulsions like wars, which now seem to be more scattered, periods of great social transformation, such as globalization, for example, emergence as one of influential agents. It is likely that the alterations provoked by societal globalization processes do produce impacts, especially because they propose a new worldview itself. In this sense, the values promoted by globalization define a wide range of aspects that stand in contrast to those of the previous world, and function as a significant counterpoint in a generational profile. This does not necessarily or automatically signify that these values have been adopted. On the contrary, they may take on individuals into expectations that society will return to a previous time, one that is believed to have been more appropriate or more correct. This seems to have been the case with the Lost Generation (the generation of the 1920s), induced framed by nostalgia for the period before the Great War. Perhaps the most precise difference between the structure of the generations of the first half of the twentieth century and subsequent generations may not be, therefore, the internal and external changes per se, but the type of change and its dynamics. The technological processes of the last quarter of the twentieth century provoked an unprecedented revolution, of depth of impact versus time of occurrence. The adjustments in worldview engendered by these changes have yet to be assessed, perhaps because the formation of generations in their historical-contextual configuration are best evaluated and conceptualized retrospectively.

\section{From the 1960s to the 1970s in Brazil: The Debate about Generations}

In general, research on the subject in Brazil has been shaped by studies of European and American origin, especially those related to a group of writers from the end of the $19^{\text {th }}$ century. The phenomenon of counterculture took root in Brazil in 1960s and 1970 s, and a considerable number of studies have been conducted, particularly concerning cultural productions in the areas of music, art, cinema, literature and theater. However, there are many differences between Brazilian and international studies. While these priorized its production based in sociology in general, Brazilian scholars mostly compare age ranges and seek explanations for the phenomenon per se, and therefore concentrated on the cultural manifestations of the 1960s. There are few studies that can be singled out as attempting to discuss the generations of the 1960s and 1970s in Brazil within the categories proposed by Mannheim and his followers.

From this standpoint, the pioneering research by Maria Alice Foracchi (1965) on youth, especially attempting to outline the social category of the student, stands out.

In exploring the identity of youth in the sixties in Brazil and in São Paulo, Foracchi paid special attention to the temporal dimensions of past and future, especially as manifested in class condition. Foracchi proposed understanding the dynamics of identity formation of youth, as "student" as a social role that developed into a difficult balancing act between dependence on the family and the conflict interstices that this dependence engendered. Complementing this, comparative studies led Foracchi to recognize dif- 
ferences in the identities of the young student (dependent on his or her family) and the young working student (one who is self-sufficient).

Sociologically, Foracchi's study commits itself to an interpretation within Mannheim's framework. It recognizes that the identity of the young student (whether dependent or autonomous) reflects a stage of life, constituted by its own style, which is to be reached as a personal destiny. Furthermore, she considered the period of youth to be a stage characterized by opposition to the world of adults, at the same time as it is a preface to a mature identity. For Foracchi, the period of youth is a unique one, with countless opportunities for innovation and invention not yet fenced off by the youth. It is in this sense, that Forrachi most closely resembles Mannheim. Still today, her work is seen not only as pioneering the topic of generation with regard to Brazilian society, but also a reference for studies on youth and youth movements.

Brazil's social climate in the 1960s, with the aggravation of the political situation and the 1964 military coup, may explain the emphasis on political topics of resistance seen in studies on generation and youth. Accompanying this phenomenon, the changes implemented in the national economy after 1964 explain approaches in the area of political science and the relationship between the market and social behavior. From The occurrence of youth movements and student organizations in the 1960s, which were very much centered around populism and nationalist ideas, followed the so-called "years of lead", a period which saw the disappearance of youth from public life.

The first person that sought to organize and critically interpret this phenomenon was Luciano Martins, who, in 1979, proposed a more comprehensive explanation for what seemed to be only an effect of political repression. For Martins, the phenomenon, which dated back to the beginning of the decade, had to do particularly with youth from the urban "middle class", and had a generational configuration. He argued that these changes occurred through three closely interrelated cultural processes within this configuration: the intensification of drug use, the deterioration of discourse, and the psychoanalytical boom. At the root of this event, which Martins called the "AI-5 generation", was the frustrated process of reaction to the military regime that had been installed in Brazil in 1964.

According to Martins, every authoritarian society engenders its own negation, forms of resistance that, in turn, may be: organized (in accordance with a hierarchy based on efficiency), pre-political, or simply reactive. The third modality is said to have prevailed in Brazil among certain segments of the urban middle class, as a consequence of the strategies adopted by the military regime to triumph and perpetuate itself. In sum, the regime installed in 1964 is said to have extended authoritarian practices beyond the purely political sphere, submitting all aspects of social life into an "authoritarian culture" which, the more dissimulated it appeared in its origin and effects, the more efficient it became.

Thus, through reducing to a minimum the scope of authoritarian practices, through their separation from their deep meaning, and through the banalization of such practices, society gradually became "accustomed" to the authoritarian principle ... 
and is permeated by the alienation it distills (Martins, 1979: p. 78).

In this way, according to Martins, two fundamental dimensions of citizenship are simultaneously hidden from the individual. Impeded from participation in political life, 1) one is alienated from the history of one's country and submitted to an arbitrary system, the origin of which is systematically disguised, and 2) one loses critical awareness.

However, what is at stake is not a purely political process; it does not occur by chance, so Martins turns to the concept of "generation". With this, what the author intends to stress is the particularly malefic consequences that this amalgam of authoritarianism and alienation had for the process of socialization of the entire social segment that crossed the border between adolescence and adulthood under the conditions of the military regime, and particularly for the AI-5 generation.

The intention of Luciano Martins' thesis was to provide a "why" to the behavior of each generation. At the same time that his work functioned as a precise historical study, it focused on generation in this case. On the eve of adulthood, he theorized, youth inquire about the meaning of their existence and seek answers in two places: the objective world (prospectively) and in their own subjective world (introspectively). Based on this combination of experiences, the young person draws up a plan for life, through which one's identity is affirmed.

Now what happened to that youth is that in the period under examination, the domains within which one was to exercise one's practice were either strictly forbidden by the regime ... or gravely contaminated by the effects produced by the "authoritarian culture" ... In that sense, it is perfectly legitimate to affirm that authoritarianism interdicted or undermined the bridges that could have more creatively linked this youth with the outer world and his or her own inner world (Martins, 1979: p. 84).

According to Luciano Martins, it is natural that under the thumb of an asphyxiating authoritarian culture, certain groups develop their own "counterculture", as a means to restore their endangered condition. However, in the case of the "AI-5 generation", things did not even get that far. Impeded on the one hand from designing a new world and, on the other, made incapable of locating the roots of the oppression to which it was subjected, individuals among the AI-5 generation wound up producing a counter-faction of the counterculture: forms of reaction that are not directed at the real cause of their problems and which, strictly speaking, have no object - they are intransitive. Therefore, this counterculture continually reiterated, through its three main components (the deterioration of discourse, drug use and the fad of psychoanalysis), the condition of psychological childhood of the individuals that comprises it. It is not that these practices, particularly the latter two, are intrinsically negative. Rather, what happened under the circumstances that created the AI-5 generation is that these practices acquired connotations that, far from promoting individual freedom, accentuated the individual's alienation from the forces that oppressed him. 
Thus, for Luciano Martins, we must disavow discourses that present drug use as an act of rebellion, a deliberate transgression of established social norms. Because, in the first place, as it is said to have occurred in the Brazilian case, the replacement of soft drugs with hard drugs, by generating compulsion and physical dependence, becomes an obstacle to the construction of the subject. Compulsion extinguished the will and, consequently, the principle of liberty. The rebelliousness ascribed to that sort of behavior, therefore, results in a simple practice of self-destruction. Furthermore, the alleged broadening of perceptive promoted by drugs is false:

This ... is a fragmented view of an artificially induced imagination that relates only

"externally" to what is real ... they are not the hidden attributes of the world that

are revealed to perception, but attributes of the kaleidoscope through which the world is seen (Martins, 1979: p. 83).

Escapes from reality that they are, drugs cannot, for this very reason, help the individual to create a design for their existence. To the contrary, to the degree that they express a refusal to get in contact with the world and with history, they contribute to the negation of the very subject.

For Luciano Martins, another characteristic of the "AI-5 generation" is the disaggregation of discourse, the outstanding characteristics of which are said to be the indetermination of terms and the restricted use of words. It is not, the author observes, a question of condemning slang, which may be thought of as a popular invention to rename something already named. Considering that language is an expression of cognitive capacity, the deterioration of discourse immediately reveals a limited perception of the world and diminished reflection on reality. The discourse of the AI-5 generation seems to have nothing to say. This communicatory incompetence translates impotence or a renunciation of explication, of knowledge of reality. Luciano concluded that where there is no critical reflection, it is impossible to build the subject.

The third component said to typify the AI-5 generation is their mass adherence to psychoanalysis (a phenomenon said to be behind the psychological boom registered in Brazil beginning in the early 1970s). For Martins, the great increase in the number of psychoanalysts during this time shows nothing but the sign of a fad. He argues that the main source of the anxiety and psychological disturbances that led individuals to seek out psychoanalysis was not neuroses, in the strict sense of the term, but rather problems induced by a specific social situation: the authoritarian regime and its culture. Because of market questions and deficiencies in the professional education of psychoanalysts, they were unable to discriminate, in their patients, their own neuroses from those derived from problems raised by the political circumstances. Thus, psychoanalysis not only resigned from the role of providing the individual with knowledge of the true causes of his psychological suffering; it also masks a social problem, attributing its exponents to subjective neuroses.

With the concept of the AI-5 generation, Luciano Martins sought to record and explain the emergence of the idiosyncratic behaviors of the social groups under consideration. For Martins, however, this explanation reveals anomalous behavioral patterns, 
particularly because of individualism and the valuation of "subjective reality" to the detriment of "social reality". If he had the pioneering clarity of vision to record this new phenomenon, Luciano Martins did not hesitate to repudiate the generation, presenting it as a perverse creature of the authoritarian regime: In this sense, to accept "subjectivity" as it exists today means subjectivity not as the subject's own space, but as the negation of it; it is to consolidate the authoritarian order that defrauds it (Martins, 1979: p. 100).

Luciano Martins' essay, a pioneering effort in the recording of a new urban culture with individualistic characteristics, was the subject of a long commentary by Jurandir Freire Costa. Grounded in the studies of Christopher Lasch (1983) and Jean Baudrillard (1995), and supported by a notable psychoanalytical reading of social life, Freire Costa took Luciano Martins' theses as a starting point for a broader discussion, the aim of which was no longer a generational stratum, the offspring of a determined political situation, but rather a new "urban ideal type", the product of profound and lasting changes in Brazilian society that were connected to the military coup, but not totally determined by it. This new "urban ideal type" is an individual in transit.

He has one foot in the universe constituted by the heritage of the bourgeois cultural tradition, and the other in the world of the values of citizenship, which tend to become hegemonic. The first universe consists of the triple axis of religion, family and property, with its corollary in the "dignity of free work". This ethical triad is seen by some as outdated and out of style, and repressive and reactionary by others. In the second, religion is contrasted with the ideology of physical-psychosexual wellbeing, the familiar old ethics of technical discourse on the normality of relationships among family members, and the ethic of work as a compulsion to superfluous consumption (Costa, 1986: p. 119).

As we see, for Costa there is more to this new social type than forced silence, incommunicability, or faddishness. The transformations he describes originate in the changes affecting Brazilian society over a period of decades, and refer not only to the psychology of this new individual but also to his family and social ethics. Thus, the author rejects the unilateral relationship posited by Luciano Martins between political authoritarianism and "subjectivist ideology". For Jurandir Freire Costa, the subjectivism of the so-called "AI-5 generation" is only a variation on the ideology of privacy, long dominant in Western societies. The military regime contributed to the strengthening of this ideology by closing off political avenues and further promoting the already present tendencies towards privatization of life and the family. At the same time, through the "economic miracle", it opened up unheard-of opportunities for social ascension. Thus what in other countries was the fruit of a long, slow historical process, in Brazil happened quickly.

Military authoritarianism created political-economic conditions that destructured the nucleus of the bourgeois family and led its members to re-define their private identities, through instruments and instances as yet non-existent or given only 
secondary importance (Costa, 1986: pp. 137-138).

For Jurandir Freire Costa, what Martins identified as the "AI-5 generation" is only part of a wider process that is typical of modern capitalist societies: the conversion of the bourgeois family to the ideologies of bodily wellbeing, sex, and psychology The product of this mass-scale transformation is the narcissistic individual

A new man, supposedly liberated, permissive and tolerant ... Profound indifference to everything not to the interest of the individual himself. Tortured by the obsession with pleasure and "authenticity", the narcissist of our times has become intransigent and tyrannical vis-à-vis everything and everyone that may perhaps stand in the way of the immediate gratification of his desires ... The happiness that is his due is the dehydrated happiness of consumption, orchestrated by merchandise advertising. Furthermore, it is a vicious circle of anxiety regarding "healthy" sexual performance, the body and "authentic" human relations. This is said to be the main reason for the blunting of his political awareness and the sharpening of "therapeutic sensibility" (Costa, 1986: p. 144).

Thus, if Costa advocates for a more ambitious analysis, having recourse to the international historical context, he ends up denying any novelty and autonomy in the generational production process. For him, the youth of Brazil and the world owe their ideology to the capitalistic world and its consumerist character. Costa argues that some of the behaviors first described by Luciano Martins should be analyzed from this perspective.

Therefore, it was not the authoritarianism of the military governments that provides the backdrop for the emergence of the AI-5 generation, as Luciano Martins suggests, but rather the development of the capitalist system in this part of the planet. The privileged relationship that should be established at the theoretical level is between the generational formation at that historical moment and the economic policy adopted by the military governments, the outcome of which was Brazil's introduction into the international capitalist system. If, because of the distance separating political science from psychoanalysis, the two authors cannot, strictly speaking, be compared on equivalent theoretical grounds, it is also true that they converge on certain points. Both authors attribute the negative value ascribed to the generation of the 1970s in Brazil, regardless of whether one prefers a theoretical framework in which the origin of the issues is a dictatorship, or one in which it is a decadent capitalism. We want to point out that, for the study of the generations, both authors set quite narrow boundaries, considering that neither saw any possibility of autonomous intervention in the 1970s.

\section{Conclusions}

The generation of the 1970s in Brazil has as yet received little analysis within the critical framework of a generational unit, whether on those points that follow Mannheim's categories, or those more related to the comparative analysis of populations. As has been pointed out above, the two authors responsible for this debate study the same 
phenomenon, but at points their conclusions vary significantly from the particular study of generations.

Perspicaciously, Luciano Martins observed that at the intersection of the 1960s and the 1970s, absolutely original behaviors were manifested in determined social segments that, because of the social expression they acquired, enabled us to talk about them as a culture. Beyond what was already recorded in that pioneering study (further widespread drug use, recourse to psychoanalysis, and a withdrawal from public life), other transformations, such as those pointed out by Costa (intense ruptures at the family level, in the conception of one's own body, and in social roles in general), seem to confirm the emergence, or at least intensification of new values that arose specifically in relation to the 1970s generation in Brazil. However, contrary to what Luciano Martins argues, this phenomenon has projected itself beyond one particular epoch or generation, becoming a more lasting pattern of behavior.

Historically, this new lifestyle may have been associated with the military dictatorship, as shown, on the subject, by the literature produced in Brazil over the past twenty years (note number 4$)^{4}$. However, admitting this historical association does not require one to accept Luciano Martins' hypotheses regarding the AI-5 generation, nor does it necessitate complete support for the causal relationship suggested by Jurandir Freire Costa.

Nevertheless, one conclusion that can be derived from both papers is that modernization has given direction to the phenomenon of generational development since the fifties. Taken as a complex process, modernization is simultaneously a set of ideas, values and behaviors, none of which has precedence over the other. In Mauss' terminology (2002), modernization is a "total social fact", ${ }^{5}$ a form of advent that also implies the adoption of the idea of progress, desire for change, desacralization of nature and social values, growing rationality, and certainly new patterns of sociability.

More specifically, modernity exalts the situation of self-centeredness, an action of an "elective nature", to use a term native to comprehensivist sociology. ${ }^{6}$ In this case, the term suggests that modernity imposes a kind of socialization in which individuals are less guided by exogenous elements, and develop internal elements guided by exogenous elements, while they develop internal elements in which elements of choice and personal planning are more strongly put forward. ${ }^{7}$ If this argument is accepted, the genera${ }^{4}$ The book by Gilberto Velho, Individualismo e Cultura (Individualism and Culture), probably marks the boundary of an area of interest. See also Figueira, Sérvula A. (Org.), a Cultura da Psicanálise. São Paulo, Brasiliense. 1985 .

5“This embraces an enormous complex of facts. These in themselves are very complicated. Everything intermingles in them, everything constituting the strictly social life of societies that have preceded our own, even those going back to protohistory. In these 'total' social phenomena, as we propose calling them, all kinds of institutions are given expression at one and the same time-religious, juridical, and moral, which relate to both politics and the family; likewise, economic ones, which suppose special forms of production and consumption, or rather, of performing total services and of distribution. This is not to take into account the aesthetic phenomena to which these facts lead, and the contours of the phenomena that these institutions manifest" (Mauss, 2002, p. 4-5).

${ }^{6}$ An extensive analysis of this idea in Latin America was written by Gino Germani (1971).

${ }^{7}$ In a way, much of Roszak's (1972) analysis of the counterculture itself as a worldwide phenomenon follows similar pathways. 
tional movements in Brazil in the sixties and seventies may be thought of in terms both of history and of group awareness; the emergence of a society with modern and more individualistic characteristics may be one element that can be used to elucidate the movements in the 1960s and 1970s. It is true that a process of modernization has external roots, but this does not imply that it therefore represents the imposition of a system, as Costa imagined.

The international context, which Costa identifies as capitalist development, could in this way be expanded to include those historical phenomena that encouraged national and regional cultures to accept another, markedly global reality. A change such as this may, depending on the culture in question, have great impacts. Although it is hard to compare the catastrophic moments of a war to economic, or even technological, change, it must be recalled that these two spheres have become more and more all-encompassing, radiating around the strong core of the world economy. Perhaps even more than this, we should note that apparently simple changes in particular territories and cultures may take on totally different characteristics when adopted by other cultures (Appadurai, 1996). Some authors have defended a general transformation in studies about generations, towards ones that consider the impacts of globalization:

This paradigm shift from a nation state frame to a cosmopolitan one-which has still to be developed methodologically-is necessary, in order to satisfy sociology's scholarly claim to engage with reality. Because social reality today is increasingly the reality of globalized modernity, characterized by the globalized freedom of movement of capital, the spread of communications and transport technologies, the establishment of global civil society movements, the emergence of global terrorist networks, etc. In the sum of these developments-and not least also through the shock of global risks and crises which are now becoming visible (Beck, 2008) - a profound break has occurred, one that also marks the relationship between the generations: the core of the self-conception of First Modernity has been affected, its fundamental premises of border, security, and rationality have become questionable. Consequently, according to our thesis, the idea of generations isolated within national boundaries is historically out of date (Beck, Ulrich, \& Beck-Gernsheim, 2009: p. 26).

Deeper analysis of the Brazilian modernization process could bring a significant contribution to academics' ability to comprehend the phenomenon, not only with regard to the generation of the sixties in Brazil, but also with regard to what until now has been called the "AI-5 generation", seen less as a detour or a mistake and more as a generational configuration. Furthermore, such a study would reinforce the significance of Martins' analysis of the impact the military regime is said to have imposed on Brazilian social life after 1964, less for its discussion of the distancing of youth from public life, and more as a catalyst of non-local phenomena.

\section{References}

Appadurai, A. (1996). Modernity at Large: Cultural Dimensions of Globalization. Minneapolis, 
MN: University of Minnesota Press.

Baudrillard, J. (1995). A Sociedade de Consumo (The Consumer Society). Lisboa: Edições 70.

Beck, U., \& Beck-Gernsheim, E. (2009). Global Generations and the Trap of Methodological Nationalism for a Cosmopolitan Turn in the Sociology of Youth and Generation. European Sociological Review, 25, 25-36.

Bourdieu, P., \& Boltanski, L. (1981). The Education System and the Economy: Titles and Jobs. In C. Lemert (Ed.), Rupture and Renewal since 1968. New York: CUP.

Costa, J. F. (1986). Sobre a Geração AI-5: Violência e Narcisismo (About AI-5 Generation: Violence and Narcissism). In Costa, Jurandir Freyre Violência e Psicanálise. Rio de Janeiro: Graal.

Dilthey, W. (1995). The Formation of the Historical World in the Human Sciences. In R. Makkreel, \& F. Rodi (Eds.), Wilhelm Dilthey Selected Works (Volume 3: pp. 101-174). Princeton, NJ: Princeton University Press.

Foracchi, M. M. (1965). O estudante e a transformação da sociedade brasileira (The Student and the Transformation of Brazilian Society). São Paulo: Companhia Editora Nacional.

Germani, G. (1971). Politica y Sociedad en una Época de Transicion: De la sociedade tradicional a la sociedad de masas. Buenos Aires: Editorial Paidós.

Groppo, L. A. (2000). Juventude: ensaios sobre a sociologia e história das juventudes modernas (Youth: Essays on the Sociology and History of Modern Youths). Rio de Janeiro: DIFEL.

Hazlett, J. D. (1998). My Generation: Collective Autobiography and Identity Politics. Madison, WI: University of Wisconsin Press.

Kehily, M. J. (2007). Understanding Youth: Perspectives, Identities and Practices. Milton Keynes: Open University Press.

Lasch, C. (1983). A Cultura do Narcisismo (The Culture of Narcissism). Rio de Janeiro: Imago.

Mannheim, K. (1952). The Problem of Generations' in Mannheim, K. Essays onthe Sociology of Knowledge (First Published 1923). London: RKP.

Maricato, E. et al (2013). Cidades rebeldes: Passe Livre e as manifestaçóes que tomaram as ruas do Brasil (Rebel Cities: Free Pass and the Demonstrations that Took to the Streets of Brazil). São Paulo: Boitempo Editorial/Carta Maior.

Martins, L. (1979). A Geração AI-5 (The AI-5 Generation), Ensaios de Opinião. Rio de Janeiro: Paz e Terra.

Mauss, M. (2002) The Gift: The Form and Reason for Exchange in Archaic Societies. London: Routledge.

Nogueira, M. A. (2013). As Ruas e a Democracia: Ensaios Sobre o Brasil (Streets and the Democracy: Essays on Brazil). Rio de Janeiro: Contraponto.

Pilcher, J. (1994). Mannheim's Sociology of Generations: An undervalued Legacy. The British Journal of Sociology, 45, 481-495.

Roszak, T. (1972). A contracultura: reflexões sobre a sociedade tecnocrática e a oposição juvenil (Counterculture: Reflections on the Technocratic Society and Youth Opposition). Petrópolis: Vozes. 
Submit or recommend next manuscript to SCIRP and we will provide best service for you:

Accepting pre-submission inquiries through Email, Facebook, LinkedIn, Twitter, etc. A wide selection of journals (inclusive of 9 subjects, more than 200 journals)

Providing 24-hour high-quality service

User-friendly online submission system

Fair and swift peer-review system

Efficient typesetting and proofreading procedure

Display of the result of downloads and visits, as well as the number of cited articles

Maximum dissemination of your research work

Submit your manuscript at: http://papersubmission.scirp.org/

Or contact ce@scirp.org 